\title{
CRÓNICA, POESÍA Y MEMORIA
}

\author{
Guillermo Acuña González*
}

Resumen: El Festival Internacional de Poesía de Quetzaltenango, Guatemala, dedicó su doceava edición a honrar la memoria y el recuerdo de las 45.000 personas desaparecidas durante el conflicto desarrollado entre las décadas de 1960 y 1990. Esta actividad literaria podría inscribirse en la denominada corriente del nuevo arte centroamericano, dedicada a reflexionar sobre los principales eventos sociales, políticos y culturales de la región. Este texto es una crónica sobre la relación entre poesía y memoria en el caso guatemalteco.

Palabras clave: poesía; personas desaparecidas; desaparición forzada; memoria; nuevo arte centroamericano; familias víctimas; historia; Guatemala.

\begin{abstract}
The International Poetry Festival of Quetzaltenango, Guatemala, dedicated its twelfth edition to honoring the memory of the 45,000 people who disappeared during the conflict between the 1960s and 1990s. This literary activity could be inscribed in the so-called stream of new art Central American, dedicated to reflect on the main social, political and cultural events of the region. This text is a chronicle on the relationship between poetry and memory in the case of persons disappeared during the Guatemalan conflict.
\end{abstract}

Keywords: Poetry; Missing People; Forced Disappearance; Memory; New Central American Art; Victim Families; History; Guatemala.

Fecha de recepción: 01/06/2017-Fecha de aceptación: 01/07/2017

* Costarricense. Máster en Comunicación Social. Doctorando en Ciencias Sociales por la Universidad Nacional, Costa Rica (UNA). Investigador del Instituto de Estudios Sociales en Población (IDESPO-UNA). Correo electrónico: guillermo.acuna.gonzalez@una.cr 
Cuando ya empieza a oscurecer, me acerqué para ver dónde estaba mi familia, encontré a 27 personas muertas pero no estaban los cuerpos de mi hija ni los de mis nietos. Sentí que alli terminaba mi semilla...tengo 82 años y no quiero morir sin saber qué pasó con ellos.

Padre y abuelo de personas desaparecidas en Ixcán, Departamento de Quiché, Guatemala ${ }^{1}$

\section{Introducción}

Es una mañana ventosa, con trazos de sol y oscuridad en San Cristóbal, Totonicapán. El viento desata los nudos y cientos de niños y niñas han tomado sus calles en espera de la magia de la palabra. El grupo ha llegado temprano y se escucha una alegre marimba que suena como si hubiera fiesta. Porque hay fiesta y seguramente habrán pájaros y soles bien altos volando sobre los cielos.

Entre el estallido de cohetes que anuncian la llegada del grupo de poetas guatemaltecos y extranjeros, aplausos y las miradas inquietas y preguntonas de los niños que se agolpan como algodones de azúcar, una minúscula figura de mujer se abre paso intentando llegar hasta la cabeza del grupo. Esta vez lo que suena no son sonidos de metralla ni bombas asesinas. Son petardos que se lanzan al aire movidos por la felicidad entera de tener poesía caminando por todo San Cristóbal. Soy testigo del momento, de ese momento y me obligo a guardar silencio para recoger en mis recuerdos las variadas formas y tonalidades de aquel día de agosto de 2016.

Año con año, el Festival Internacional de Poesía de Quetzaltenango -en adelante, FIPQ ${ }^{-2}$ regala uno de los momentos más emotivos a los pobladores y a los mismos poetas participantes, al programar una caminata que recorre las principales calles de la ciudad de San Cristóbal, que se prepara con todos sus honores para recibir la palabra y el asombro. Hemos caminado, por ello, algunas cuadras del bello San Cris, como le llaman coloquialmente a la ciudad, en un marco de festividad que apenas resguarda el sentido homenaje que brinda en esta ocasión el Festival, que cumple doce años de realizarse

1 Comité Internacional de la Cruz Roja -en adelante, CICR-, Guatemala, los familiares de las personas desaparecidas: un compromiso de todos. Estudio del Comité Internacional de la Cruz Roja (CICR) sobre la situación de las familias de las personas desaparecidas a raíz del enfrentamiento armado en Guatemala. Misión para Guatemala (2010), 44.

2 El Festival Internacional de Poesía de Quetzaltenango es una iniciativa cultural y social que en agosto de 2016 cumplió su doceava edición ininterrumpida. Sus distintas versiones han contado con la presencia de innumerables poetas y escritores de varias partes del mundo. 
de forma ininterrumpida. No en vano el lema oficial que lo presenta indica que está dedicado a la memoria, vida y obra de las personas desaparecidas en Guatemala. $^{3}$

La principal pregunta que orienta un esfuerzo de recuperación de una actividad de dicha magnitud consiste en ubicarla en el marco de manifestaciones artísticas de muy diversa naturaleza que se han venido desarrollando a lo largo de la región centroamericana, como estrategias desarrolladas para articular tejido social, momento histórico y acciones de reivindicación contemporánea.

\section{El contexto}

Desde que recibí la invitación para participar en el encuentro con mi trabajo literario y con mis aportes como académico preocupado por los temas de las movilidades humanas en la región, me embargó un enorme sentimiento de gratitud, pero sobre todo, de reflexión. No es fácil nombrar el dolor, renombrarlo; no es fácil traerlo al presente en una sociedad que como la guatemalteca aún no cierra las heridas del conflicto, que todavía no sana completamente pese a los esfuerzos realizados por innumerables personas para que se conozca en todos sus extremos los acontecimientos y la verdad de lo ocurrido durante un período de su historia reciente.

Hablar sobre el tema de los desaparecidos en un país como Guatemala implica hacer referencia a un período de la historia reciente, ubicado en un marco de treinta años que van desde 1960 hasta 1996, y denominado en algunos estudios como la época de la violencia institucional. ${ }^{4}$

Al promediar los años noventa, con la firma de los acuerdos de paz, se puso fin a décadas de virulento desarrollo en aquel país centroamericano y se abrieron entonces otras dinámicas y procesos orientados a aclarar lo que había ocurrido en años previos. Torres Rivas indica que lo ocurrido en Guatemala en aquel momento no puede ser catalogado estrictamente como guerra civil, sino como un período caracterizado por "momentos guerrilleros" y 36 años de

3 El CICR considera como persona desaparecida a toda aquella de la que sus familiares desconocen su paradero, que haya sido dada por desaparecida a consecuencia de conflictos armados, situaciones de violencia, desastres naturales o procesos migratorios, entre otras causas. CICR, Guatemala, los familiares de las personas desaparecidas ..., 1.

4 Para ver períodos en los que se ubican estos acontecimientos, se recomienda revisar el texto de Patrick Ball, Paul Kobrak y Herbert Spirer, Violencia institucional en Guatemala, 1960 a 1966: una reflexión cuantitativa (Nueva York, EE. UU.: American Association for the Advancement of Science; Centro Internacional para Investigaciones en Derechos Humanos, 1999), 13, disponible en URL:

https://www.hrdag.org/wp-content/uploads/.../state-violence-guate-1999-espanol.pdf. 
represión en manos del ejército y el poder estatal. ${ }^{5}$ Seguramente habrá lecturas diversas sobre las causas y la naturaleza misma del conflicto guatemalteco, pero coincidentes en cuanto a los efectos devastadores para cientos de miles de personas y sus familiares.

Ciertamente, nos encontramos en presencia de un proceso marcado por el ejercicio del poder y por la actuación directa y abierta de actores que tuvieron responsabilidad en la desaparición de miles de personas del contexto guatemalteco. En aquellos años, niños, niñas, jóvenes, académicos, intelectuales, artistas y personas del ámbito civil fueron vistos por última vez quizá por sus familiares o amigos cercanos y pasaron a engrosar las filas de una nada despreciable suma de 45.000 personas desaparecidas.

Hablar sobre tales escenarios, verbalizarlos, implica reconocer un contexto de incertidumbre que muchos de los implicados, sobre todo victimarios, se empecinan en no volver a recordar, pese a que el olvido sea medicina poco recomendable si se quiere reconstruir la vida para quienes han perdido un familiar. Implica establecer una acción política contra el olvido, el silencio y la impunidad sobre los que algunos pretenden refundar la nación guatemalteca. ${ }^{6}$

El espíritu de esa memoria contra el olvido quedó expresado por la poeta y académica guatemalteca Carolina Escobar Sartí, durante la ceremonia de entrega de la Rosa de la Paz a Marvin García, director del festival, en las instalaciones del Palacio Nacional, el día 1 de agosto de 2016: "Las personas desaparecidas desaparecen dos veces: cuando se van y cuando las olvidamos".

Aún el mismo acto no deja de ser simbólico, en un momento de la historia guatemalteca en que diversos sectores locales hacen ingentes esfuerzos por honrar la vida y la memoria de quienes un día desaparecieron sin dejar rastro.

Las secuelas del conflicto todavía se hacen presentes. En las calles anchas y claras de la capital o en los parajes rurales del interior guatemalteco, se respira un continuo dolor, mezclado con dinámicas recientes en las que la desigualdad, la exclusión y el racismo estructural siguen pesando en aquel país. En una suerte de herida que no sana del todo, como lo ha indicado el Comité de la Cruz Roja Internacional:

5 Edelberto Torres-Rivas, La piel de Centroamérica. Una visión epidérmica de setenta y cinco años de su historia (San José, Costa Rica: FLACSO, 2007), 114.

6 Sergio Villena Fiengo, "Intervenciones intempestivas en Centroamérica. El anti-ceremonial público en la obra de Regina José Galindo", Revista de Estudios Globales y Arte Contemporáneo (España) 3 n. 1 (2015): 192, URL: http://revistes.ub.edu/index.php/REGAC/article/ view/12407. 
"El enfrentamiento armado que afectó a Guatemala durante tres décadas ha dejado graves secuelas en toda la población del país, y en particular, en los familiares de las víctimas. A pesar de los años que han pasado desde el fin del enfrentamiento armado, la incertidumbre sobre el paradero de un ser querido sigue siendo una dura realidad para muchas familias". 7

Y también con gestos de esperanza para las personas afectadas, como el enjuiciamiento, en enero de 2016, de catorce militares acusados por la desaparición de 558 indígenas durante la época del conflicto armado, específicamente entre 1981 y 1988.

\section{Memoria y poesía}

Es una mañana ventosa, llena de alegría en San Cristóbal. Pienso en lo paradójico que resulta que un grupo de poetas y escritores estemos desplegando la palabra, justamente en una comunidad que forma parte del Departamento donde se produjo la primera masacre luego de la firma de los acuerdos de paz: la denominada Masacre de la Cumbre Alaska.

No hace mucho, por cierto, y como lo describe el jesuita y antropólogo guatemalteco Ricardo Falla:

"Desde Quetzaltenango ya me enteré de las noticias. Había habido muertos y el Ministro de Gobernación, el teniente coronel Mauricio López Bonilla, junto con el Ministro de Defensa, general Ulises Anzueto, declaraban -con la seguridad acostumbrada de que nadie los contradiga- que el equipo que llevaba la policía y el equipo de reserva del ejército era de "armas no letales" y que los heridos se debían a enfrentamientos tumultuosos. Si ni la policía ni el ejército iba armado con armas de fuego, las muertes se habían provocado entre los manifestantes mismos. Aducían que la mayoría de campesinos heridos presentaba la señal del uso de machetes. Los manifestantes eran presentados como turbas peligrosas. Estas versiones me recordaron, inmediatamente, aunque no tenía información para contradecirlas, los partes del ejercito en tiempos del conflicto armado, cuando había masacre de civiles".

7 CICR, Guatemala, los familiares de las personas desaparecidas..., 7.

8 Ricardo Falla, “Toto, 4/10/12: primera masacre del ejército tras la firma de la paz”, Plaza Pú- 
La figura menuda del inicio de esta crónica, que se abre paso entre la gente, resulta ser Mayarí de León, hija del escritor guatemalteco Luis de Lión - José Luis de León Díaz-, desaparecido sin dejar rastro en 1984, una fecha infeliz cuando se trabaja con el tema de la memoria, al decir de la investigadora argentina Elizabeth Jelin. Autor de innumerables obras que contaban la opresión del indígena por parte del ladino guatemalteco, el escritor se convirtió en una personalidad artística y política molesta para los gobiernos de entonces, razón que pudo haber provocado su desaparición forzada y presunta posterior ejecución extrajudicial.

En 2004, su familia presenta una demanda asesorada por la Fundación Mirna Mack ante la Comisión Interamericana de Derechos Humanos. Como producto de la demanda, el Estado guatemalteco reconoce su responsabilidad institucional en la desaparición forzada del escritor y su presunta ejecución extrajudicial, ocasionada por la inteligencia militar del ejército de Guatemala durante la época del conflicto armado. "Es el primer caso de 45.000 ocurridos en Guatemala que se logra un reconocimiento en estos términos", informa la página. Testigo mudo de un tiempo preciso, el año de su desaparición, le sobrevive un texto hermoso, tal vez premonitorio:

\section{"Cuando volvás}

Te esperaré con un canasto para recibir tu alegría.

Con estos crayones pintaré tus paisajes.

Amor,

si es invierno

mis manos tendrán guardado el calor del verano.

pero si no llegara,

vos sabés cuales son mis deberes.

Seguramente habré salido, puntual, a cumplir uno de ellos;

un deber de días, de meses.

Puede que también uno tenga que morirse y eso puede durar años.

y si no basta estar muerto,

habrá que convertirse en polvo y eso puede durar siglos.

Y vos sabés que no se puede volver, que eso es parte de la más alta disciplina.

De otro modo, podremos no cumplir correctamente nuestro oficio de parteros.

así pues

nada de lágrimas.

blica, 13 de noviembre de 2012, URL: https://www.plazapublica.com.gt/content/toto-41012primera-masacre-del-ejercito-tras-la-firma-de-la-paz. 
Vos sabés que aquí la lluvia siempre es abundante y para qué hinchar más la tierra.

mejor aprovechá su humedad y árala profundamente, sembrale todas las semillas que traigás y esperá atenta.

Puede que sintás mi respiración en una de las germinaciones".

Como un acto de mantener viva la memoria y el legado de su padre, Mayarí dirige una hermosa marimba magistralmente ejecutada por niños, niñas y jóvenes guatemaltecos -Marimba Proyecto Luis de Lión-, llevando el mensaje de la esperanza y el reconocimiento de los que ya no están por todo el territorio. Es un proyecto artístico, político, pero sobre todo humano. Resulta hermoso verlos tocar la marimba a algunos de ellos que apenas la alcanzan. Así, pienso, deberían ser los sueños de los niños y niñas en esta región del planeta: con ilusión, con alegría, con esperanza, como tocando una marimba.

Observo entonces su menuda figura fundirse en un largo y sentido abrazo con Marvin, el director del festival. De una carpeta saca papeles y una de las fotografías de su padre, que siempre los acompaña en sus eventos. La observo detenidamente y en ese momento cobran sentido para mí las palabras con las que se empezaba cada lectura en comunidades, plazas, cárceles, escuelas, colegios, universidades, sitios sagrados, tanto en Ciudad Guatemala como en la bella Quetzaltenango:

"Decidimos este año alzar nuestras voces para llamar a
nuestros desaparecidos, unimos nuestras palabras a la
lucha inclaudicable de quienes los buscan, tan suyos los
cuerpos, tan nuestros, llamamos con amor a cada uno de
ellos, le hemos pedido a la tierra que nos señale su destino,
le hemos pedido al cielo que ilumine la luz de la justicia,
buscamos a nuestros desaparecidos porque es el destino
de nuestros pueblos encontrarlos, es el destino de nuestras
palabras no olvidarlos nunca". ${ }^{10}$

El investigador Sergio Villena utiliza la noción nuevo arte centroamericano para hacer referencia justamente a los procesos que tienen como tarea urgente ajustar cuentas con un pasado traumático reciente, en un momento en que, desde el poder, se anuncia la promesa de la paz, la

9 Véase: https://proyectoluisdelion.org/.

10 Véase: Festival Internacional de Poesía de Quetzaltenango: http://www.fipq.org/. 
democracia y la modernización. ${ }^{11}$ Para responder a este desafío, equiparable con el de "unir con la sangre del poeta la columna quebrada de la bestiasiglo" -haciendo referencia a un texto del poeta ruso Osip Maldestam, de 1923-, el arte centroamericano ha trabajado sobre la memoria, interviniendo intempestivamente en los espacios públicos y los ceremoniales oficiales, con el fin de interpelar al conjunto de la sociedad. Concluye Villena:

"La reconstrucción de la memoria de la represión política y sus secuelas en tiempos democráticos ha recibido una importante atención tanto en la literatura como en las artes visuales. En las letras, existe una importante producción de poesía, cuento y novela testimonial, pero también se han recopilado múltiples testimonios y se han llevado adelante investigaciones, llegando incluso a conformarse proyectos y redes de alcance regional". ${ }^{12}$

Por esta razón, entiendo que el FIPQ se incorpora en su doceava edición a estos procesos de nuevo arte regional, procurando establecer canales y mecanismos para visibilizar en una sociedad como la guatemalteca los horrores de un pasado reciente que es necesario visibilizar en el presente, para su entendimiento y superación. En esta línea, por cierto, la edición de 2017 estará dedicada a visibilizar la situación de la niñez desaparecida en el contexto guatemalteco. Porque sí, hablar de desaparecidos y memoria en un país como Guatemala implica referirse a 45.000 personas que ya no están físicamente, pero continúan perdurando en la mente y el cuerpo de sus familiares.

Del total de personas desaparecidas, número consensuado por diversos organismos de derechos humanos, acompañamiento y asistencia a los familiares de las personas desaparecidas, solo cerca de 3.000 cuerpos han podido ser exhumados, identificados y sus restos devueltos a sus familiares para recibir alguna despedida, alguna ceremonia de cierre según sus creencias. ${ }^{13} \mathrm{El}$ poeta y productor audiovisual quetzalteco Julio Serrano Echeverría recrea con puntualidad el momento de la exhumación:

11 Villena Fiengo, 177.

12 Ibid, 177-178.

13 Otros informes reveladores que es posible revisar son el Informe de la Misión de Verificación de las Naciones Unidas -MINUGUA, 2004- y el informe Recuperación de la Memoria Histórica de Guatemala, conocido como informe REHMI -Recuperación de la Memoria Histórica-. Al respecto, véase: http://www.remhi.org.gt/portal/category/acerca-de/. 
"A un cuerpo devuelto a su familia

Hay que matar coche, quemar cohetes, disparar estrellas contra el cielo.

Vamos a bailar, madrecita, a sacudir el polvo, a destaparle la boca al guaro que hoy deja de raspar, guaro que cura, guaro que abona, guaro que se hace grito, llanto sonriente al fin.

Ahora que sos puro hueso, dejo mi beso en tu calavera como el sereno del amanecer y salgo un momento a cortar flores". ${ }^{14}$

De esa cifra, dolorosa, actual, permanente, sobresale una con esperanza. De los niños y niñas y personas menores de edad desaparecidos en aquellos años del conflicto - cerca de 5000, según cifras aportadas por CALDH-, ${ }^{15}$ unos ochocientos han sido identificados y han logrado reencontrarse con sus familiares en años recientes. Solo en el año 2015 se produjeron 53 de esos reencuentros.

\section{Nombrar a los ausentes}

En medio de este contexto, enfrentarse a la narrativa de las personas desaparecidas implica encontrarse con la resignificación de categorías utilizadas para definir a los actores a quienes impactó el conflicto durante tres décadas. Por eso, al escuchar a Helen Mack ${ }^{16}$ hablar en un foro por la paz y la

14 Julio Serrano Echeverría, Actos de magia (San José, Costa Rica: Ediciones Espiral, 2012), 30.

15 "Un cielo de colores en memoria de 45.000 desaparecidos de guerra en Guatemala", EFE, 21 de junio de 2016, URL: http://www.efe.com/efe/sociedad/un-cielo-de-colores.

16 Helen Mack ostenta el Premio Nobel Alternativo de la Paz como resultado de su incansable lucha por que se reconociera la responsabilidad del Estado guatemalteco en el asesinato de 
dignificación de los desaparecidos, sobre los familiares de las personas desaparecidas como las víctimas, adquiere una connotación distinta en la forma en la que las personas se posicionan frente al dolor y hacen suyo el silencio. Como lo plantea el Comité Internacional de la Cruz Roja:

"Las personas que desaparecen son víctimas en primera persona, pero también lo son sus familiares. Cuando esto sucede, se genera en la familia un profundo sufrimiento y una incertidumbre constante que produce afectaciones físicas, emocionales y psicosociales, a las que frecuentemente se le suman dificultades legales y económicas. Dado que quienes desaparecen forman parte de una comunidad, ésta también se verá profundamente afectada". ${ }^{17}$

En el mismo informe se señala la existencia de diferencias sustantivas entre el ámbito urbano y el rural. En el primer caso, las personas desaparecidas eran líderes estudiantiles, jóvenes como Marco Antonio Molina Thiessen, de catorce años, desaparecido en 1981 por agentes del ejército que irrumpieron en su casa como una forma de cobrarse la fuga de su hermana, detenida por su apoyo a la guerrilla. Líderes sindicales -como los que formaban parte del grupo desaparecido en 1980 y en cuya memoria se instaura el 21 de junio como el Día Nacional Contra la Desaparición Forzada en Guatemala-, profesores universitarios, académicos y artistas como el ya nombrado escritor Luis de Lión o la poeta y periodista Alaide Foppa, en cuya figura recayó el homenaje a la memoria, vida y obra de los desaparecidos en el marco del FIPQ.

Foppa desapareció la mañana del 19 de diciembre de 1980 junto a su chofer. No vivía en Guatemala pero regresaba cada cierto tiempo para renovar sus reflexiones en torno a la realidad guatemalteca. Su práctica feminista, intelectual y política pudo haberle costado su desaparición. Su trabajo literario también era profundo:

$$
\text { "Adiós }
$$

Con los ojos de la despedida

Os vi aquel día, Cosas de nuestra vida,

La vida parecía

Una cosa perdida.

La casa estaba vacía

su hermana, Myrna Mack.

17 Ibid, 1. 


\section{En la hora de la despedida, \\ Y sin embargo quedaban \\ Las cosas de nuestra vida". ${ }^{18}$}

En el caso del escenario rural, cientos de personas desaparecieron de sus comunidades; se trataba de poblaciones indígenas y campesinas, principalmente. En uno y otro caso, dice el informe de la Cruz Roja, lo que media y diferencia es el tratamiento de las noticias y la visibilización recibida por parte del interés público.

Durante los días en que transcurrió el Festival al que acudimos más de treinta poetas de México, España, Uruguay, Palestina, Japón, El Salvador, Costa Rica, República Dominicana, Honduras, Colombia y Guatemala, cientos de veladoras fueron encendidas en cada lectura. Una instalación de una muestra fotográfica sobre las desapariciones antecedió la apertura y la clausura, acompañada de veladoras y el respeto absoluto de las personas que pasaban por los sitios donde se realizarían las actividades, y una muestra del fotógrafo italiano Daniele Volpe -auspiciada por el CICR en su sede en Guatemala- llamada Sukel -en español, "Buscando"- tomó los principales espacios públicos de las ciudades guatemaltecas, como testigo de las imágenes que atraviesan cuerpos, familias, biografías.

Las lecturas y actividades fueron acompañadas por la labor más que loable de la Fundación de Antropología Forense de Guatemala (FAFG), cuyos representantes dedicaron jornadas de información y la toma de muestras referenciales de ADN, como aporte para la búsqueda de las personas desaparecidas.

\section{¿Dónde están?}

La principal pregunta que todavía al día de hoy se siguen haciendo los familiares de esas 45.000 personas desaparecidas en Guatemala es: ¿dónde están? Se enfrentan a una continua necesidad de saber, que no terminará hasta que conozcan verdaderamente la situación de quienes les fueron arrancados.

La respuesta, a todas luces, no resulta sencilla porque implica la referencia a un momento histórico que partió para siempre la realidad guatemalteca.

El 21 de junio de 2016, como muchos otros 21 de junio en los últimos años, familiares de las personas desaparecidas se reunieron en la plaza central de Guatemala para rendir homenaje y recordar a los suyos lanzando al cielo globos blancos y rojos, como una forma de mantener viva su memoria y su vida. Llamaron a esa actividad: "45.000 razones para no olvidar".

18 Véase: https://www.poemas-del-alma.com/alaide-foppa-adios.htm. 
Justamente, en febrero de ese año, se aprobó por parte del Congreso Guatemalteco la iniciativa 3.590 para crear la Ley de la Comisión de Búsqueda de Personas Víctimas de Desaparición Forzada y Otras Formas de Desaparición. Esta comisión, de carácter autónomo, velaría durante quince años por la búsqueda de la verdad sobre las denuncias de desapariciones forzadas durante el período de 1960 hasta 1996.

La caminata en San Cristóbal sigue ferviente y animada por una marimba que nos ha acompañado durante todo el trayecto. Cientos de niños nos abrazan, nos preguntan, nos sonríen. Prefiero pensar en ellos como cuerpos con esperanza, una vida completa que será vivida como se debe. Pienso en el libro que di a uno de ellos, como muestra de mi agradecimiento por el calor y las energías recibidas esa mañana. Cuando abre la solapa y ve mi fotografía en ella, me dice con contundencia: "Este no es usted". Y sí, probablemente tenga razón, porque mi asistencia al festival y mi reconocimiento sobre una problemática tan actual y dolorosa, pero a la vez esperanzadora, me habrán cambiado para siempre. 